\title{
Flower Bud Differentiation in Quercus suber L.
}

\author{
Maria Carolina Varela ${ }^{1}$, Teresa Valdiviesso $^{1^{*}}$, Elisa Novelli ${ }^{2,3}$, Cândida Sofia Trindade ${ }^{1}$
}

(1) National Institute for Agricultural and Veterinary Research, Strategic Research Unit and System Services Agrarian, Forestry and Plant Protection., Av. da República, Quinta do Marquês P-2780-157 Oeiras, Portugal; (2) Catholic University of the Sacred Heart, Institute of Agricultural and Environmental Chemistry, 84 Emilia Parmense, I-29100 Piacenza, Italy; (3) Centre for Research on Sustainable Development in Agriculture (OPERA), 84 Emilia Parmense, I-29100 Piacenza, Italy

* Correspondence: e-mail: teresa.valdiviesso@iniav.pt
Citation: VARELA MC, VALDIVIESSO T, NOVELLI E, TRINDADE CS 2016 Flower bud differentiation in Quercus suber L.. Southeast Eur for 7 (1): 65-70. DOI: http://dx.doi. org/10.15177/seefor.16-02

Received: 19 Nov 2015; Revised: 15 Dec 2015; Accepted: 28 Dec 2015; Published online: 18 Jan 2016

\begin{abstract}
Background and Purpose: Cork oak (Quercus suber L.) is one of the most important forest species growing in the Western Mediterranean region. This investigation intends to assess the timing of flowering differentiation of cork oak and contribute to the deepening of the knowledge about the process of the sexual reproduction of the species.

Materials and Methods: In 2010 four trees were selected $(9,14,24,25)$ from a plot of 25 trees located at Quinta da Serra, Portugal. A total of 240 buds were collected from these four trees, on three days ( 8,14 and 23 March), from 4 branches per tree and 5 positions per branch for the assessment of meristem differentiation.

Results: Meristem differentiation analysed on the sampling days revealed there were only vegetative structures by 8 March; a few male and female primordia on 14 March; and fully differentiated reproductive structures on 23 March.

Conclusions: Flowering sex determination of cork oak occurs about one month before the flowering onset.

Keywords: bud histology, cork oak, flower sexual determination, meristem differentiation, phenology
\end{abstract}

\section{INTRODUCTION}

Cork oak (Quercus suber L.) is one of the most important forest species growing in the Western Mediterranean region and it provides the only natural and renewable product for making wine stoppers. Apart from stoppers, cork also provides raw-material for vast panoply of industrial products that enhance the great ecological value of cork oak for the Mediterranean ecosystem [1].

Sexual reproduction in cork oak is the key process to generate genetic diversity for its evolution and adaptation and the dynamics of the flowering processes plays an important role in gene flow and population kinship [2, 3].

Cork oak is a monoecious species with sub-continuous growth, annual and biennial fruiting, while the prevalent flowering occurs in spring in unisexual inflorescences. Atypical male and female flowering events may occur, especially the autumn / winter male flowering [4].

The reproductive cycle, flower morphology, as well as leaf and seed development have been studied by several authors for different Quercus species [5, 6]. Reproductive phenology for Quercus suber has been studied by Varela and Valdiviesso [2] and Varela et al. [3], but flowering differentiation timing has not been studied so far.
In a plot studied through long run observations on reproductive behaviour since 1993 [7, 8], we selected four trees with the aim to assess the timing of flower differentiation in cork oak, by identification of the internal structures of the buds. The results provide new insights useful in reproductive biology studies, flowering prediction and climatic influence on the reproductive process.

\section{MATERIAL AND METHODS}

\section{Plant Material and Site Characterization}

The studies were carried out, during 2010, on a permanent plot in the cork oak forest "Quinta da Serra" located in the centre of Portugal $\left(38^{\circ} 29^{\prime} 14^{\prime \prime} \mathrm{N}, 09^{\circ} 0^{\prime} 31^{\prime \prime} \mathrm{W}\right.$, $116 \mathrm{~m}$ altitude) near Azeitão. The site's edaphoclimatic conditions are very favourable for cork oak. The stand comes from natural regeneration, it is irregularly spaced, unevenly aged, and is intensively managed for cork production. The climate is typically Mediterranean, smoothed by oceanic influence, with 4-5 months of drought, an average maximum temperature of $29.0^{\circ} \mathrm{C}$, an average minimum temperature of $8.3^{\circ} \mathrm{C}$ and the mean annual rainfall of $690 \mathrm{~mm}$.

The controlled and permanent plot includes 25 trees within an area of about 1.5 ha. The trees have been used 
for long run population genetic studies since 1993, analysing the reproductive behaviour at the level of flowering/fruiting ability and flowering phenology. Flower and fruit production is evaluated by degrees of 1, 2 and 3 [3]:

- degree 1 - null or negligible production of male flowers or fruits,

- degree 2 - about half of the productive part of the crown exhibits male flowers or fruits,

- degree 3 - the tree exhibits male flowers or fruits in large quantity.

For this study we chose four trees $(9,14,24$ and 25) with a discriminating pattern of reproductive profile characterized from 1993 to $2009[7,8]$, and assessed in terms of phenology, the amount of male flowering and acorn production (Figure 1).

Regarding bud burst and male flowering phenology, tree 24 was always the first to flower and above plot-average on male flowering quantity and acorn production; tree 14 was late in phenology, with a large quantity of male flowers and average in acorn production; tree 9 was intermediate in phenology, with a large quantity of male flowers and under plot-average in acorn production. Tree 25 was added to the plot in 2009 due to significant atypical female flowering by the end of June.

The choice of the sampling dates as well as the number of buds per branch (5) was based on our previous knowledge [7, 8] about the species and plot flowering behaviour. The study used a total of 240 buds. In each tree we picked four branches and five buds per branch on three days (8, 14, and 23 March) to a total of 60 buds per tree. On each tree the branches were randomly chosen and the buds were numbered from 1 to 5 (from top to bottom). After collecting these sampling data, we also collected the material during flowering season (13 May) needed for the assessment of gamete synchronization and embryo development (9 October).

\section{Histology}

Buds were fixed, during at least 48 hours, in FAA 1:1:18 - formalin:acetic acid:ethanol $(70 \%)$ at $4^{\circ} \mathrm{C}[9,10]$. Hydration was achieved through progressive ethanol/water series. Buds were put into polyethylene glycol - PEG. Embedded specimens were sectioned on a rotary microtome Reichert in increments of $10 \mu \mathrm{m}$ and were stained with tuluidine blue. Permanent mounts were prepared using Canada balsam for light microscope observation.

Digital images of the histological sections were obtained with a ProgRes ${ }^{\circledR}$ CapturePro 2.8 - JENOPTIK Optical Systems coupled to an Olympus BX41 microscope, and were electronically processed using the software ProgRes ${ }^{\circledR}$ Systeme - JENOPTIK Optical Systems.

\section{RESULTS}

\section{Meristem Differentiation}

Through histological observation we could identify four stages of meristem differentiation within the buds:

- vegetative (Figure 2a),

- differentiated for reproductive structures but sexually undetermined (Figure $2 b$ ),

- primordium of male flowers with anther primodia developed (Figure 2c),

- primordium of female flowers/vegetative, i.e. mixed buds which are in accordance with cork oak ovuliferous flowers' developmental behaviour that occurs always at the axil of the new leaves (Figure $2 \mathrm{~d}$ ).

Means for male flowering and acoorn production (degree) 1993-2010

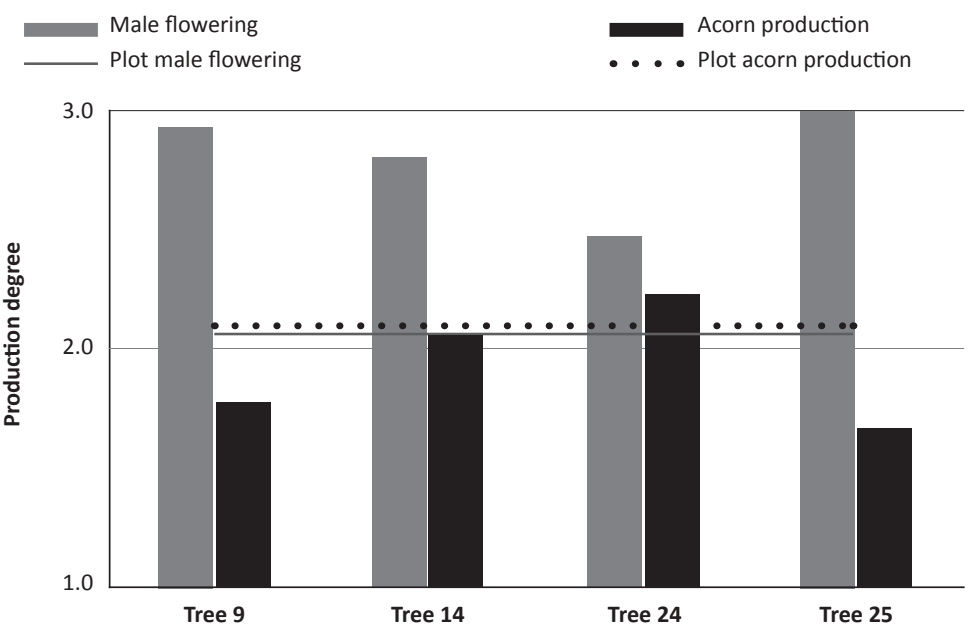

FIGURE 1. Male flowering and acorn production of Quercus suber trees selected for the study based on degree rate: degree 1 - null or negligible production of male flowers or fruits; degree 2 - about half of the productive part of the crown exhibits male flowers or fruits; degree 3 - the tree exhibits male flowers or fruits in large quantity. Trees are compared through the mean production from 1993 to 2010. 


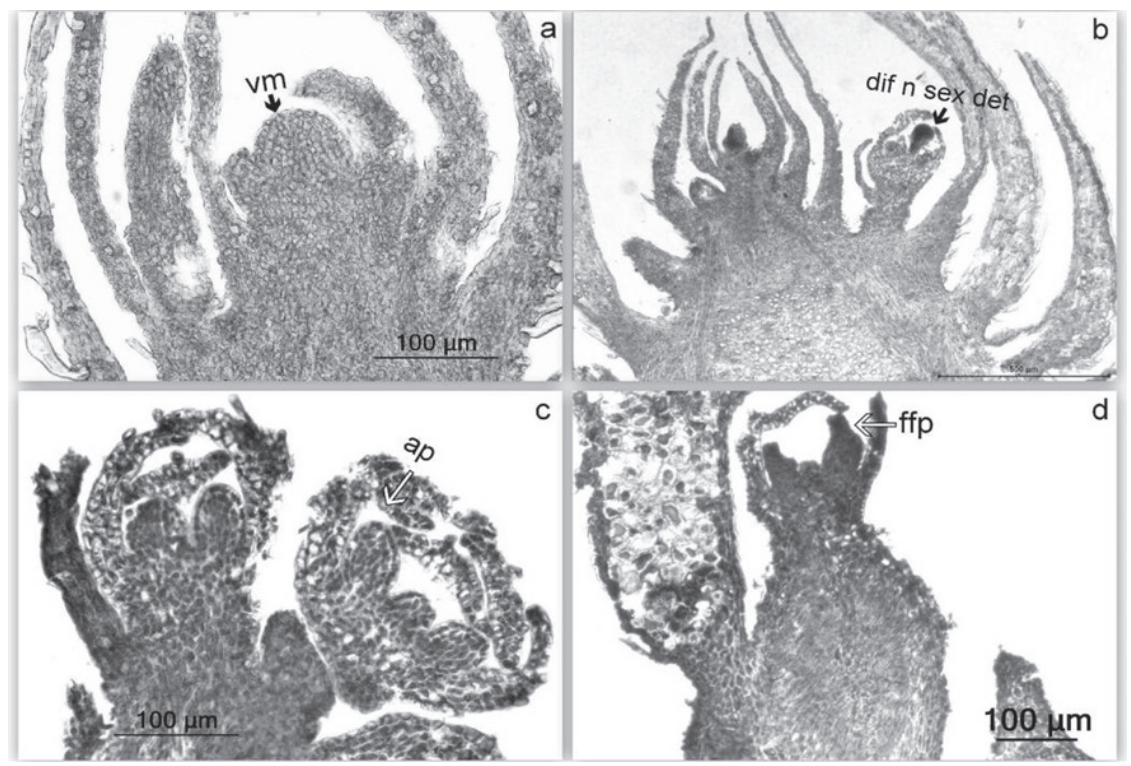

FIGURE 2. Histological longitudinal sections of key bud stages: a) vegetative bud (vm - vegetative meristem), b) differentiated bud without sexual determination (dif $n$ sex det), c) primordial of male inflorescence (ap - anther primordium), d) female inflorescence (ffp - female flower primordium).

On 8 March, all the trees had meristematic activity dominated by leaf primordium (vegetative structures). A small part of the buds already had meristematic differentiation, but without sexual determination being therefore classified as "Sex-Undetermined". Sexual determination was patent only on a very small proportion of the buds for male flowers and only on trees 14 and 24 (Figure 3a, b). No sex differentiated structures were visible on buds in position 2 and female structures were patent only on buds in position 4 . On this day tree 9 and tree 25 revealed to be the latest on sex flower determination.

On 14 March about $40 \%$ of structures were still "SexUndetermined" on trees 14, 24 and 25 (Figure 4a, b). Tree 9 had the smaller proportion of "Sex-Undetermined" structures and the higher amount of anther-primordia developed structures. On this day ovuliferous flowers were evident in all buds except in position 1. For all positions the proportion of "Sex-Undetermined" meristematic development was still significant.

On 23 March, all structures were fully determined on all four trees studied (Figure 5a, b). Undifferentiated structures were no longer present and sexual structures were already defined. Male flowering was dominant on buds in positions 2 and 4 . Tree 9 kept the pattern of male flowering dominance over the ovuliferous structures, which is consistent with the pattern observed during the period of 1983-2010. a) Bud stage by tree on 8 March

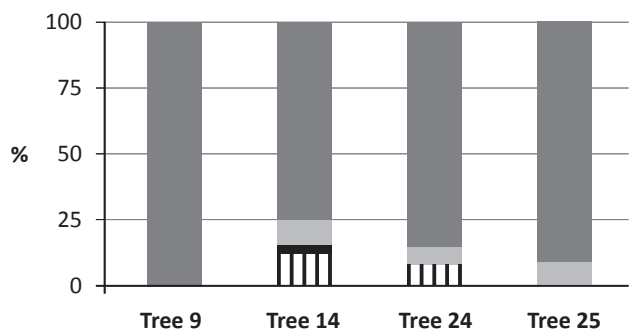

b) Bud stage by position on 8 March

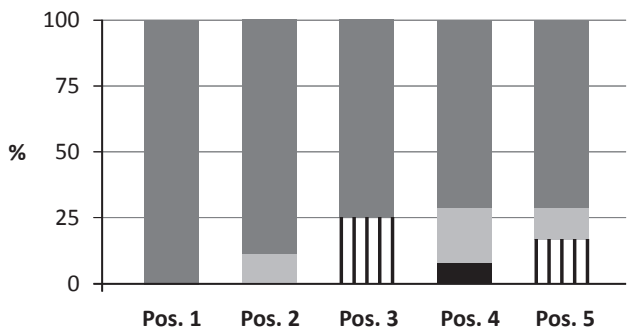

FIGURE 3. Quantification of bud determination comparing tree and bud positions (pos.) on a branch (veg - vegetative, ind - undifferentiated, / /veg - primordia of female inflorescences with vegetative buds, primordia of male inflorescences by 8 March 2010). 
a) Bud stage by tree on 14 March

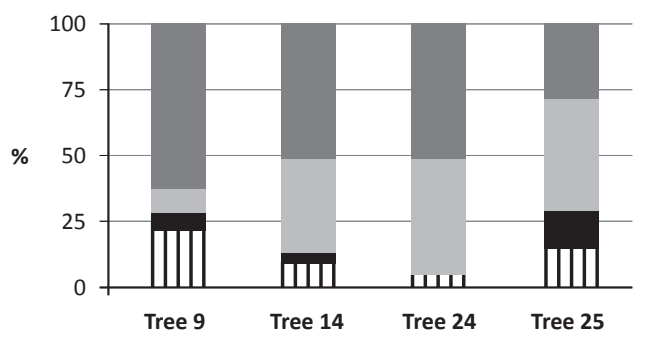

b) Bud stage by position on 14 March

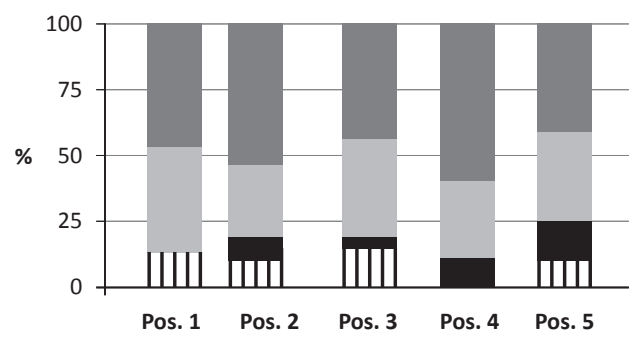

veg ind

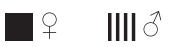

FIGURE 4. Quantification of bud determination comparing tree and bud positions (pos.) on a branch (veg - vegetative, ind - undifferentiated, + /veg - primordia of female inflorescences with vegetative buds, primordia of male inflorescences at 14 March 2010).

After the last samplings, we also collected the material during flowering season for the assessment of gamete synchronization and embryo development (between 13 May and 9 October).

On 13 May we found male flowers in different phenological stages, both on and between trees, although four trees maintained the characteristic time lag phenological profile. A part of male flowers were immature, before anthesys, having the tetrads visible (Figure 6a) and another part with dehiscent anthers had pollen grains fully developed (Figure 6b). On the same date female flowers were externally formed and receptive in general, but ovules were immature, exhibiting only primordia as patent in Figure 6c. On 9 October the fruits were not mature but the embryo was completely formed (Figure 6d) i.e. one or two months before acorn falling.

\section{DISCUSSION}

On 8 March, about 6-8 weeks prior to flower emergence, the meristematic activity was dominated by leaf primordia (vegetative structures) and only a few sex- determined structures were patent, with male dominance. Yet leaf primordia which were visible may envelop axillary meristem which will evolve for female flowers. On 14 March, differentiation towards sex determination was in progress, but the sex of many of the inflorescences remained of undetermined profile. Only on 23 March, about one month prior to the emergence of flowers, both male and female inflorescences were clearly sexually defined.

With the histological observations of samplings in May we could confirm the immaturity of the female gametophyte during the pollination phase [4]. In October we found that although the fruit was still in development, the embryo was fully formed.

Further observations over a period of several years on trees of different reproductive behaviour and under different climatic/weather conditions should be performed in order to obtain a comprehensive model for Quercus suber.

Since no signs of aborted structures from the opposite sex were visible at any flower primordia, we considered the hypothesis that cork oak's unisexual flowering is of 'type II' [11], i.e. sex determination occurs before the initiation of stamens and carpels. a) Bud stage by tree on $\mathbf{2 3}$ March

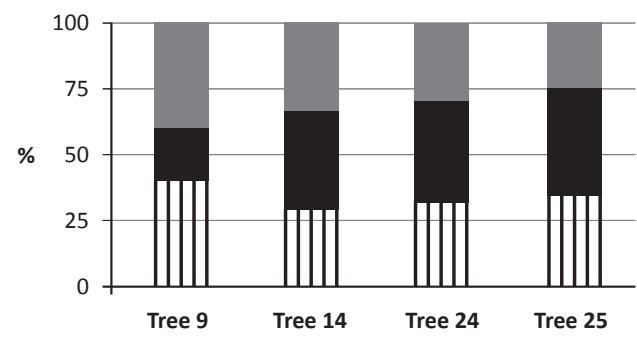

b) Bud stage by position on 23 March

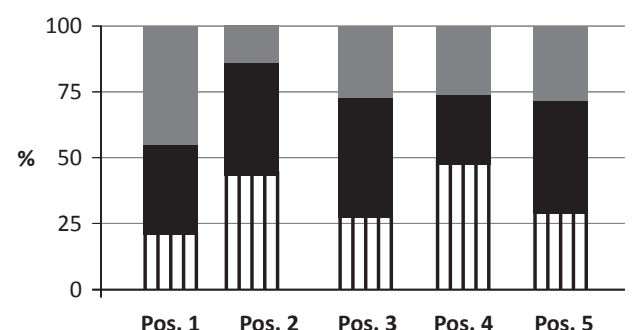

$\begin{array}{lllll}\text { Pos. } 1 & \text { Pos. } 2 & \text { Pos. } 3 & \text { Pos. } 4 & \text { Pos. } 5\end{array}$

FIGURE 5. Quantification of bud determination comparing tree and bud positions (pos.) on a branch (veg - vegetative, ind - undifferentiated, + /veg - primordia of female inflorescences with vegetative buds, primordia of male inflorescences at 23 March 2010). 


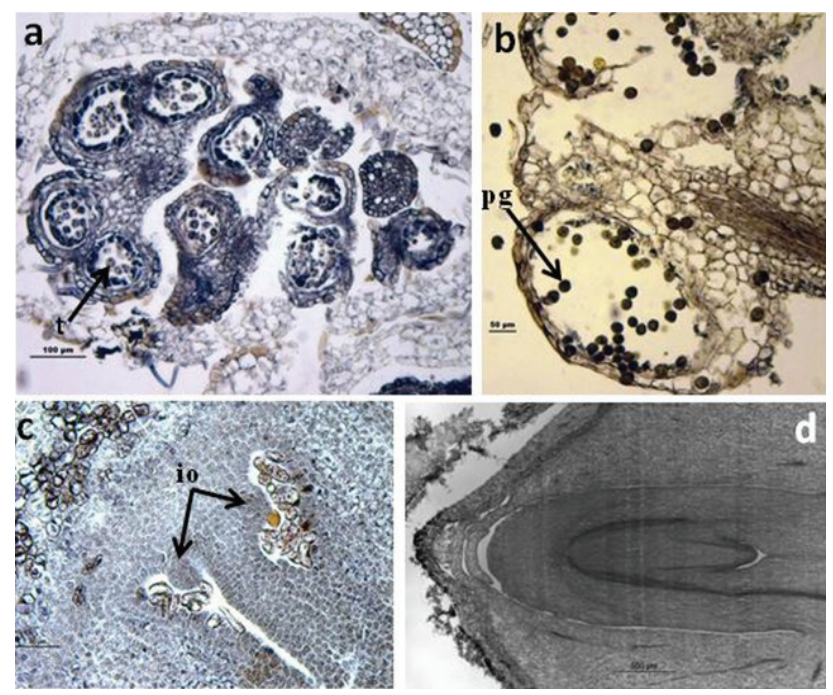

FIGURE 6. Histological sections on 13 May: a) male flower with tetrads (t), bar $100 \mu \mathrm{m}$; b) pollen grains (pg) within an anther, bar $50 \mu \mathrm{m}$; c) female flower with immature ovules (io), bar $50 \mu \mathrm{m}$ on 9 October; d) embryo completely formed, bar $500 \mu \mathrm{m}$.

The results point out that the flowering sex determination in cork oak may occur very late devoid of well-defined differentiation season as it happens with the Fagacea species Juglans regia [12] and Castanea sativa [13] which is consistent with the sub-continuous growing profile of the species.

If the pattern observed in this study will remain in other regions of cork oak distribution, reliable flowering prediction by bud sampling, for further use on flowering genomics, fruiting preview, gender balance on seedorchards, the management of effective size on conservation of genetic resources on endangered small populations, shall be performed only about one month before bud burst is foreseen.

\section{CONCLUSIONS}

The results indicate that at Quinta da Serra the flowering sex determination of cork oak occurs in close proximity to the flowering onset, i.e. about one month ahead, which is consistent with the sub-continuous growing profile of the species.
The results of the histological study confirmed the longrun phenological and reproductive profile of the selected trees, reinforcing that the behaviour is systematic and most likely under genetic control. Indeed the tree 24 was the first to begin bud differentiation which is in accordance with its early flowering phenology and tree 9, whose flowering profile is predominantly male, was the one with higher percentage of male primordia.

We consider that the results provide useful insights for the management of acorn production, the conservation of genetic resources, the adaptation of the species under climate change scenarios and evolution.

\section{Acknowledgements}

We would like to thank Quinta da Serra owners by facilitating access to the plot.

\section{Funding}

Project NATO Science of Peace "Preventive and Remediation Strategies for Continuous Elimination of Poly-Chlorinated Phenols from Forest Soils and Ground Waters" (SfP - 981674) for the PhD grant of Elisa Novelli.

\section{REFERENCES}

1. VARELA MC 2007 Processo do Símbolo da Cortiça, CorkMark Ed. EFN-INIA, Oeiras, Portugal

2. VARELA MC, VALDIVIESSO T 1996 Phenological phases of Quercus suber L. flowering. Forest Genetics 3 (2): 93-102

3. VARELA MC, BRÁS R, BARROS IR, OLIVEIRA P, MEIERROSE C 2008 Opportunity for hybridization between two oak species in mixed stands as monitored by the timing and intensity of pollen production. Forest Ecol Manag 256 (8): 1546-1551. DOI: http://dx.doi.org/10.1016/i.foreco.2008.06.049
4. NATIVIDADE JV 1950 Subericultura. Direção Geral dos Serviços Florestais e Aquícolas, Lisboa, Portugal, $387 \mathrm{p}$

5. SORK VL, BRAMBLE J, SEXTON O 1993 Ecology of mastfruiting in three species of North American deciduous oaks. Ecology 74: 528-541

6. DOCOUSSO A, MICHAUD H, LUMARET R 1993 Reproduction and gene flow in the genus Quercus L. Ann For Sci 50 (Suppl. 1): 91-106. DOI: http://dx.doi.org/10.1051/forest:19930708 
7. VARELA MC, VALDIVIESSO T, GENOSUBER CONSORTIUM 2014 Controlled pollination in cork oak (Quercus suber L.) to support its genome sequencing project. Poster presentation on the 23rd International Congress on Sexual Plant Reproduction, Porto, Portugal, 13-18 July 2014

8. VARELA MC 2015 Reproductive behaviour and clonal stump/root propagation and consequences for sustainable genetic variability in cork oak and holm oak in Portugal. In: Proceedings of the II International Congress of Silviculture Designing the future of the forestry sector, Firenze, Italy 2629 November 2014. In print.

9. JOHANSEN DA 1940 Plant Microtechnique. McGraw-Hill Ed, New York, USA
10. RUZIN SE 1999 Plant microtechnique and microscopy. Oxford University Press, NewYork, USA, 322 p. DOI: http://dx.doi. org/10.1046/i.1365-2818.2000.00673.x

11. DIGGLE PK, DI STILIO VS, GSCHWEND AR, GOLENBERG EM, MOORE RC, RUSSELL JRW, SINCLAIR JP 2011 Multiple developmental processes underlie sex differentiation in angiosperms. Trends Genet 27 (9): 368-376. DOI: http:// dx.doi.org/10.1016/i.tig.2011.05.003

12. VALDIVIESSO T 1991 Biologia floral da nogueira (J. regia L.). Master Dissertation, INIA-ENFVN, Alcobaça, Portugal $85 \mathrm{p}$

13. VALDIVIESSO T 1999 Estudo Sobre a Reprodução Sexuada e Caracterização de Cultivares de Castanea sativa Mill. PhD Dissertation, INIA-EFN Lisboa, Portugal 131 p 